\title{
Experimental Characterization of Heat Transfer in an Additively Manufactured Polymer Heat Exchanger
}

\author{
Martinus. A. Arie*, Amir H. Shooshtari*1, Ratnesh Tiwari*, Serguei V. Dessiatoun*, Michael M. \\ Ohadi*, Joshua M. Pearce** \\ * Smart and Small Thermal Systems Laboratory, Department of Mechanical Engineering, \\ University of Maryland, College Park, MD 20742, USA \\ ** Department of Materials Science \& Engineering and Department of Electrical \& Computer \\ Engineering, Michigan Technological University, Houghton, MI 49931, USA
}

\footnotetext{
${ }^{1}$ Corresponding Author

Department of Mechanical Engineering

2181 Glenn L. Martin Hall, Building 088

University of Maryland, College Park, MD 20742, USA

Tel.: +1 3014055412 .

E-mail address: amir@umd.edu
} 


\section{Abstract}

In addition to their low cost and weight, polymer heat exchangers offer good anticorrosion and antifouling properties. In this work, a cost effective air-water polymer heat exchanger made of thin polymer sheets using layer-by-layer line welding with a laser through an additive manufacturing process was fabricated and experimentally tested. The flow channels were made of $150 \mu \mathrm{m}$-thick high density polyethylene sheets, which were $15.5 \mathrm{~cm}$ wide and $29 \mathrm{~cm}$ long. The experimental results show that the overall heat transfer coefficient of 35-120 W/m² $\mathrm{K}$ is achievable for an air-water fluid combination for air-side flow rate of 3-24 $\mathrm{L} / \mathrm{s}$ and water-side flow rate of $12.5 \mathrm{~mL} / \mathrm{s}$. In addition, by fabricating a very thin wall heat exchanger (150 $\mu \mathrm{m})$, the wall thermal resistance, which usually becomes the limiting factor on polymer heat exchangers, was calculated to account for only $3 \%$ of the total thermal resistance. A comparison of the air-side heat transfer coefficient of the present polymer heat exchanger with some of the commercially available plain plate fin heat exchanger surfaces suggests that its performance in general is superior to that of common plain plate fin surfaces.

Keywords: Polymer heat exchanger, plastic heat exchangers, advanced heat exchangers, layer-by-layer line welding additive manufacturing, process intensification

\section{Nomenclature}

$\begin{array}{ll}A_{H} & \text { Heat transfer area }\left[\mathrm{m}^{2}\right] \\ A_{\text {front }} & \text { Frontal area }\left[\mathrm{m}^{2}\right] \\ C & \text { Heat capacity }[\mathrm{W} / \mathrm{K}]\end{array}$




$\begin{array}{ll}C_{r} & \text { Heat capacity ratio [-] } \\ c_{p} & \text { Specific heat }[\mathrm{J} / \mathrm{kgK}] \\ D & \text { Hydraulic diameter [m] } \\ h & \text { Heat transfer coefficient }\left[\mathrm{W} / \mathrm{m}^{2} \mathrm{~K}\right] \\ k & \text { Thermal conductivity }[\mathrm{W} / \mathrm{mK}] \\ L & \text { Length [-] } \\ \dot{m} & \text { Mass flow rate }[\mathrm{kg} / \mathrm{s}] \\ N T U & \text { NTU [-] } \\ p & \text { Pressure [Pa] } \\ \Delta p & \text { Pressure drop [Pa] } \\ Q & \text { Heat exchanger heat duty }[\mathrm{W}] \\ R & \text { Thermal resistance }[\mathrm{K} / \mathrm{W}] \\ R e & \text { Reynolds number [-] } \\ R e_{\text {nom }} & \text { Nominal Reynolds number }[-] \\ S & \text { Ratio of major axis of ellipse }[-] \\ r_{\text {out }} & \text { Channel outer radius [m] } \\ r_{i n} & \text { Channel inner radius [m] } \\ T & \text { Temperature [C] } \\ U & \text { Overall heat transfer coefficient }\left[\mathrm{W} / \mathrm{m}^{2} \mathrm{~K}\right] \\ U_{X} & \text { Uncertainty of } X \\ U_{y} & \text { Uncertainty of } Y \\ \dot{V} & \text { Volumetric flow rate }[\mathrm{L} / \mathrm{s}] \\ Y & \text { Calculated quality } \\ X & \text { Dependent variables of } Y\end{array}$

\section{Greek Letters}
$\varepsilon_{H X}$
Heat exchanger effectiveness [-]
$\mu$
Dynamic viscosity $[\mathrm{kg} / \mathrm{ms}]$

\section{Subscripts}

$\begin{array}{ll}\text { air } & \text { Air-side } \\ \text { HX } & \text { Heat exchanger } \\ \text { in } & \text { Inlet } \\ \text { out } & \text { Outlet } \\ \text { seg } & \text { Segment } \\ \text { wall } & \text { Wall-side } \\ \text { water } & \text { Water-side }\end{array}$

\section{Abbreviations}

$\begin{array}{ll}\text { AM } & \text { Additive manufacturing } \\ \text { CNT } & \text { Carbon nanotube } \\ \text { DAQ } & \text { Data acquisition system } \\ \text { FFF } & \text { Fused filament fabrication }\end{array}$




$\begin{array}{ll}\text { HDPE } & \text { High density polyethylene } \\ \text { HX } & \text { Heat exchanger } \\ \text { PLA } & \text { Polylactic acid } \\ \text { VSC } & \text { Variable speed controller }\end{array}$

\section{Introduction}

The development of polymer heat exchangers has received significant attention in the last decade due to several favorable properties of polymers such as corrosion resistance, low weight, low cost, ease of manufacture and many others. The anticorrosion and antifouling properties are major advantages of polymer based heat exchangers over metallic based heat exchangers, as corrosion and fouling can significantly reduce the lifetime and performance of a metallic heat exchanger. Polymers are also much lighter than metals, and thus use of polymer heat exchangers can reduce the cost of the support structures. In addition, the polymers are generally much cheaper than metals. Also, polymers are good electrical insulators, which makes them suitable for applications such as electronics cooling. Lastly, the polymers have greater chemical resistance than metal, which makes them more durable as a heat exchanger material. Numerous works have been reported in the literature about the development of polymer heat exchangers. Summaries of the progress on polymer heat exchangers can be found in [1-4].

However, the lower thermal conductivity of the polymers is a major disadvantage (thermal conductivity $(k)$ ), is about $0.3-0.5 \mathrm{~W} / \mathrm{mK}$ for polyethylene compared to $16 \mathrm{~W} / \mathrm{mK}$ for stainless steel or $205 \mathrm{~W} / \mathrm{mK}$ for aluminum). Several approaches are being used to mitigate this disadvantage, such as improving the thermal conductivity by the use of fillers [5-10] or reducing the wall thickness of heat exchangers [1]. Several researchers have reported success in improving the thermal conductivity of polymers by adding carbon nanotube (CNT) fillers. Depending upon the properties of CNT fillers, their orientation, and the overall volume fraction of the fillers, resulting thermal conductivities of the polymers between 5 and $41 \mathrm{~W} / \mathrm{mK}$ have been reported in the literature [5]. However, this improvement of thermal conductivity increases the 
cost of the polymers. In addition, adding a filler material can increase the weight of the material, as filler like graphite yields higher density than the base polymer.

Several different types of polymer heat exchangers have been developed depending upon the applications. One of the most common polymer heat exchangers is the shell and tube heat exchanger type for liquidliquid heat transfer applications [11-13]. However, due to the low thermal conductivity of polymers, the wall thickness has become a limiting factor for such applications. Liu et al. compared the performance of a polymer shell and tube heat exchanger with metallic shell and tube heat exchangers, and showed that the wall thermal resistance of the polymer heat exchanger is much larger than the metallic one [12].

Another common type of polymer heat exchanger is the polymeric hollow fiber heat exchanger [1, 14-17]. It consists of hundreds to thousands of small polymer tubes bundled together at both ends to form a honeycomb structure. The geometry is similar to a shell and tube heat exchanger except that it does not have baffles and thus can operate either in cross flow or parallel flow configurations. It can be used for single-phase or condensing liquid-to-liquid heat transfer applications. In order to offset the low thermal conductivity of the polymer, the heat transfer area per volume is increased by increasing the number of tubes per bundle as compared to conventional heat exchangers. As many as 12,100 tubes per bundle have been reported [18]. A study by Zarkadas and Sirkar shows that the performance of the polymeric hollow fiber heat exchangers is comparable with metallic shell and tube heat exchangers [14].

Another type of polymer heat exchanger that is widely available in the market is the plate heat exchanger. Several types of polymer plate heat exchangers are commercially available, such as those from $\mathrm{AB}$ Segerfrojd [19] and Ail Research [20]. There has been significant research and development on plate polymer heat exchangers in recent years [21-24]. Cheng and Van Der Geld experimentally tested a polymer plate fin heat exchanger for air-water and air/steam-water heat transfer applications and reported overall heat transfer coefficient of $80-130 \mathrm{~W} / \mathrm{m}^{2} \mathrm{~K}$ for air-water fluid pair [22]. The limitation of low thermal conductivity in the majority of these heat exchangers has been overcome by ensuring small wall thickness. 
In this work, a cost effective polymer heat exchanger based on prime surface technology was fabricated using a layer-by-layer line welding additive manufacturing (AM) technique of thin, high density polyethylene (HDPE) sheets. Additive manufacturing is an emerging fabrication technique that has shown significant advantages over conventional methods due to its ability to fabricate complex geometries which otherwise would be very challenging or impossible to fabricate using conventional means. However, despite its advantages there has been only limited work in implementing additive manufacturing for heat exchanger fabrication. Some of the reported works, such as those by Harrish et al. [23], Cormier et al. [25], Tsopanos et al. [26], Arie et al. [27, 28], and Zhang [29], have shown some success in the use of AM for metallic heat exchanger fabrication. The reported works on the use of additive manufacturing for polymer heat exchanger fabrication is even more limited. In addition to the issue of poor material thermal conductivity, this could be attributed to some additional AM challenges such as wall porosity and liquid absorption. One notable work on polymer heat exchanger fabrication in the literature is by Cevallos, who successfully fabricated a webbed tube heat exchanger using fused deposition modeling [30].

The layer-by-layer line welding additive manufacturing technique used in this study was introduced by Denkenberger et al. [31] and offers the potential for previously economically prohibitive applications of heat exchangers such as vehicle heat recovery ventilators [32]. The technique uses an automatically controlled laser to selectively weld the layers of polymer sheets. The depth of the weld is carefully controlled to make sure that only the desired layer is welded and not the layers beneath. One of the advantages of this fabrication method is that this technique uses premade polymer sheets. Therefore, the issue of wall porosity commonly observed in other AM methods can be eliminated. Another advantage is that heat exchangers with wall thickness as low as $150 \mu \mathrm{m}$ can be fabricated.

The prime surface polymer heat exchanger consists of water channels through which hot water flows. These channels are cooled by air that flows through the gap between the water channels as shown in Fig. 1. A water channel was fabricated by welding two polymer sheets (150 microns thick) together. The location of the welding is shown in Fig. 1(b). The wall thickness of the sheets is very small, and thus it does not require 
expensive polymer blends of higher thermal conductivity. The fabrication process and experimental testing of the heat exchanger will be discussed in further detail later in this paper.

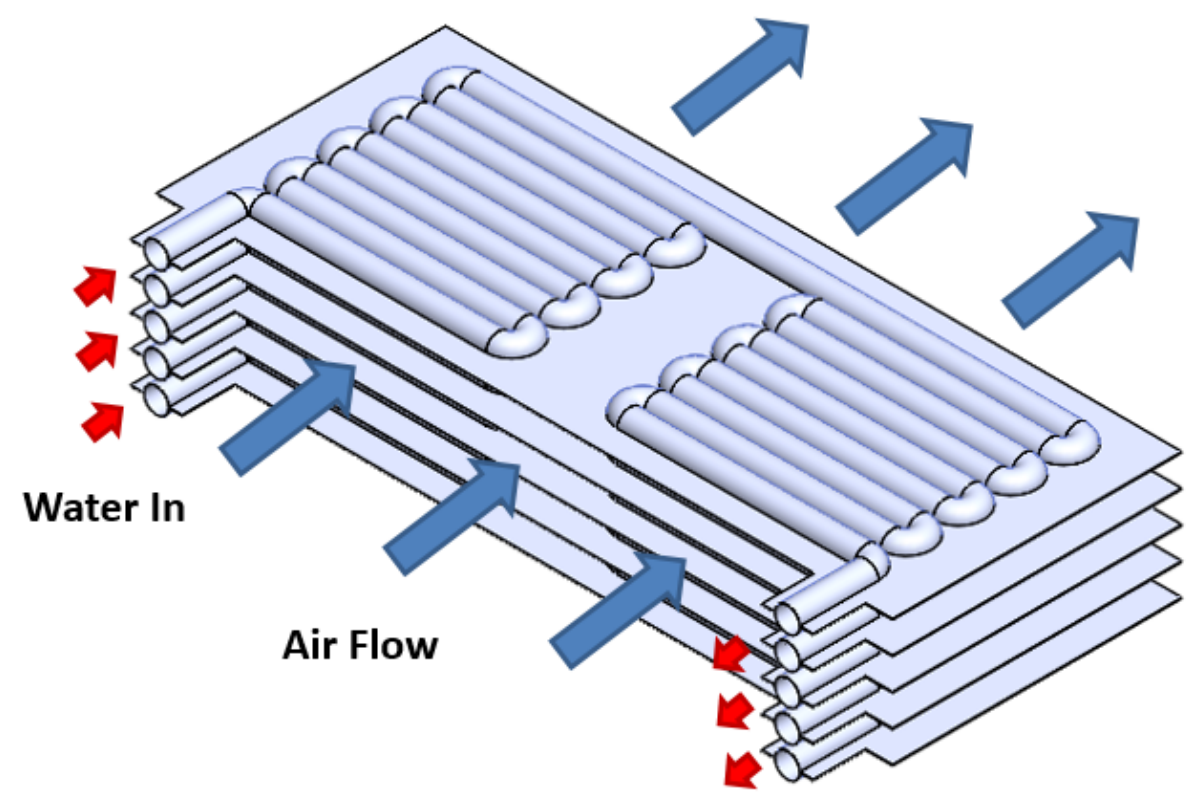

Water

(a)

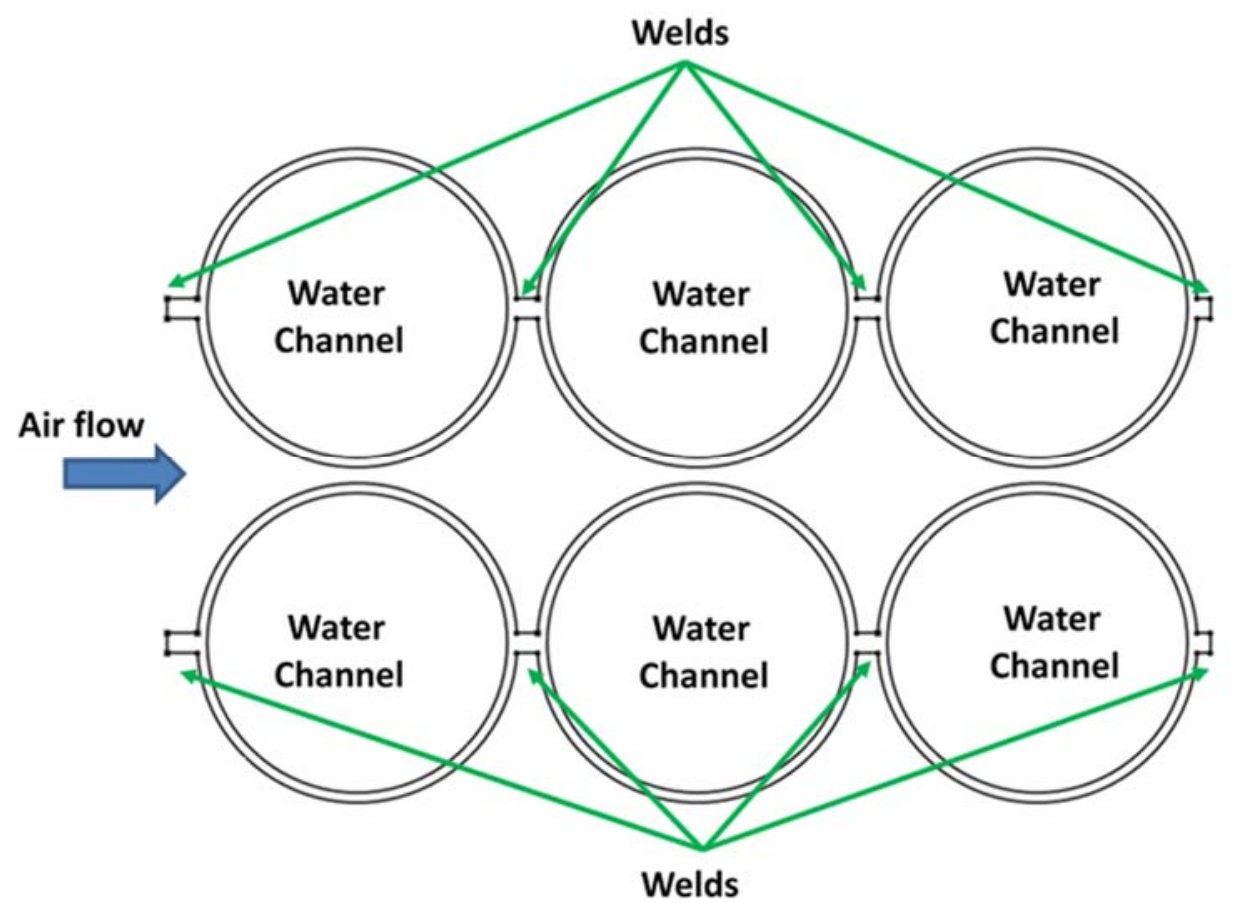

(b)

Fig. 1: The prime surface heat exchanger used for the current study: (a) Isometric view (b) Cross-section view 


\section{Heat Exchanger Geometry and Fabrication}

A schematic of the 3-D laser welding machine used to fabricate the heat exchanger is shown in Fig. 2. It is based off of the self-replicating rapid prototype (RepRap) electronic, controls and hardware architecture [33-35]. The welding machine consists of a fiber laser that can be moved on the $\mathrm{x}$ - and $\mathrm{y}$-axes using stepper motor to position the laser, frames and 3-D printed joints to support the laser and motors, and a printer bed where the polymer sheets are placed [36]. A summary of the fabrication technique is also shown in Fig. 2 and details of the systems assembly and operation in Ref. [36]. First, two sheets of HDPE were set on top of each other. Then, a water channel was formed by welding both sheets together based on a preprogrammed digital model and open-source Franklin control software [37]. Although the unit that was fabricated and tested in this study consisted of only a single stack, the fabrication process can be repeated to build multi-stack heat exchangers using the same concept. A more detailed explanation of the layer-bylayer line welded additive manufacturing technique can be found in Ref. [31].

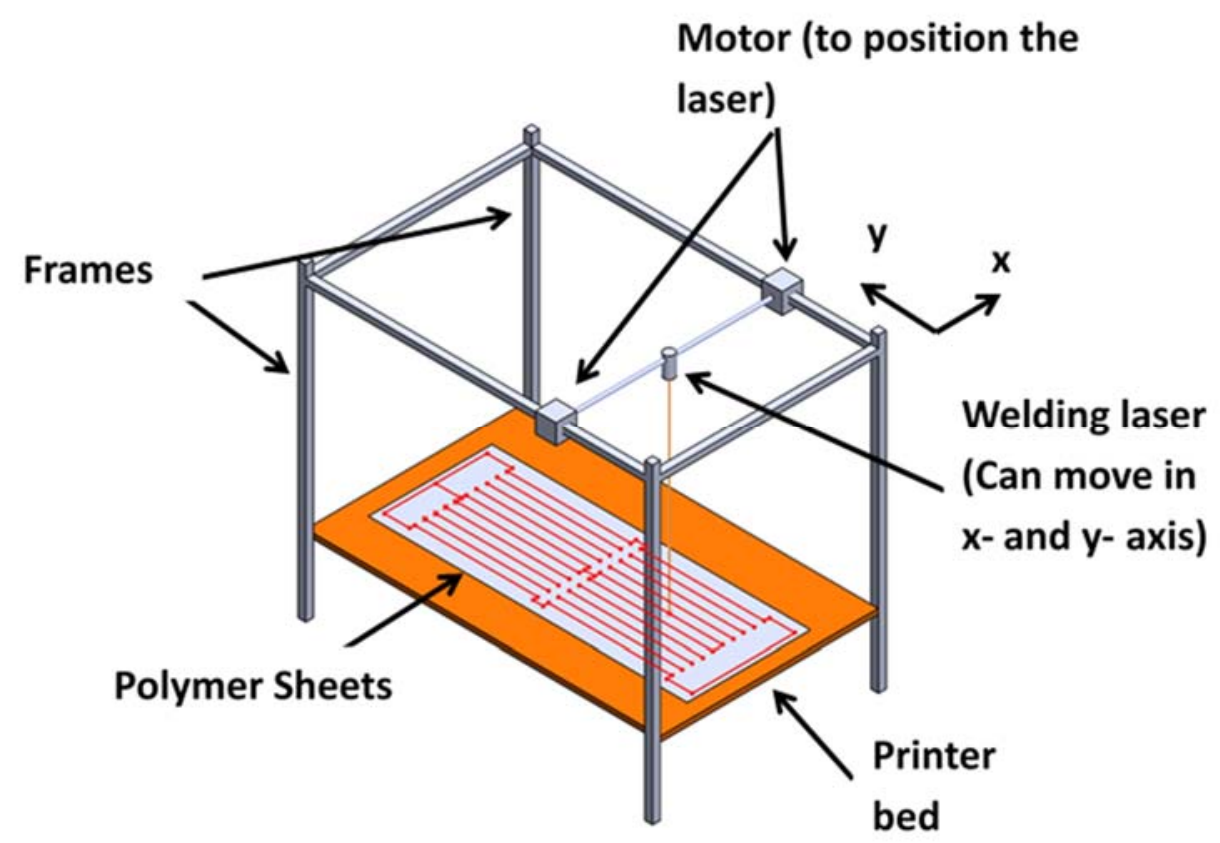

Fig. 2: Layer-by-layer line welded additive manufacturing technique 
A CAD drawing of the fabricated polymer heat exchanger is depicted in Fig. 3(a). In order to maximize the heat exchanger effectiveness, the water channel is formed in multipass manner. This allows the water to be cooled down by passing air over the channel multiple times as shown in Fig. 3(a). Since the heat exchanger has only a single unit layer instead of a stack of multiple layers, a header was fabricated to accommodate the air flow to allow for performance testing. The header also acts as housing for the polymer heat exchanger core as shown in Fig. 3(b). The header was fabricated using 3-D fused filament fabrication (FFF) printing using polylactic acid (PLA) material using a standard RepRap. When the flow is applied into the channels of the test section, the flow channels expand, resulting in a slight reduction in overall size of the heat exchanger as shown in Fig. 3(b). The gap between the heat exchanger core and the header served as air channel as shown in Fig. 3(c). It should be noted that the header is needed only to determine heat transfer in the prototype and will not be required in a heat exchanger with multiple stacks of polymer layers as shown in Fig. 1(a). Since the channel takes tubular shape after the expansion of the polymer, the air gap between the test section and header is not uniform and has a corrugated shape. The channel gap varies from $0.6 \mathrm{~cm}$ to $0.12 \mathrm{~cm}$ depending upon curvature of the water channel. In order to fix the position of the flexible heat exchanger core, small cylindrical rods were added as a support structure to the heat exchanger core as shown in Fig. 3(b) and (c).

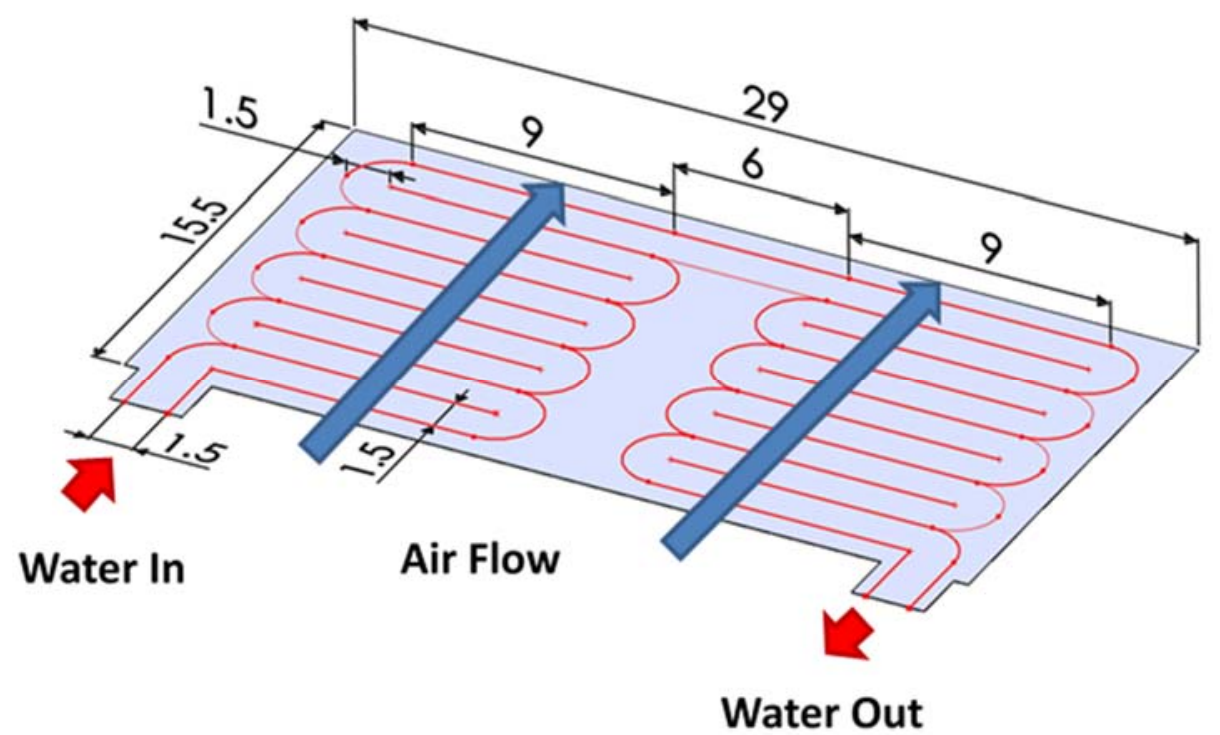

(a) 


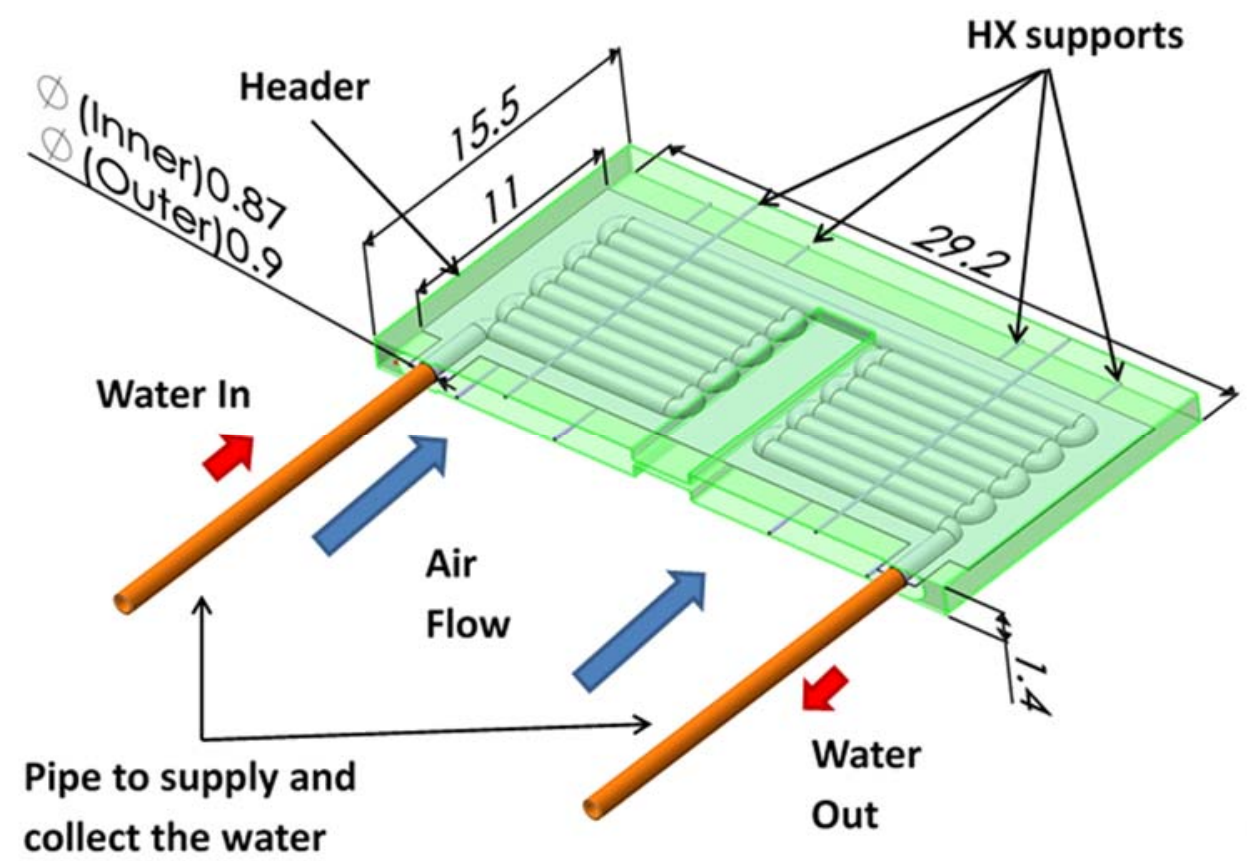

(b)

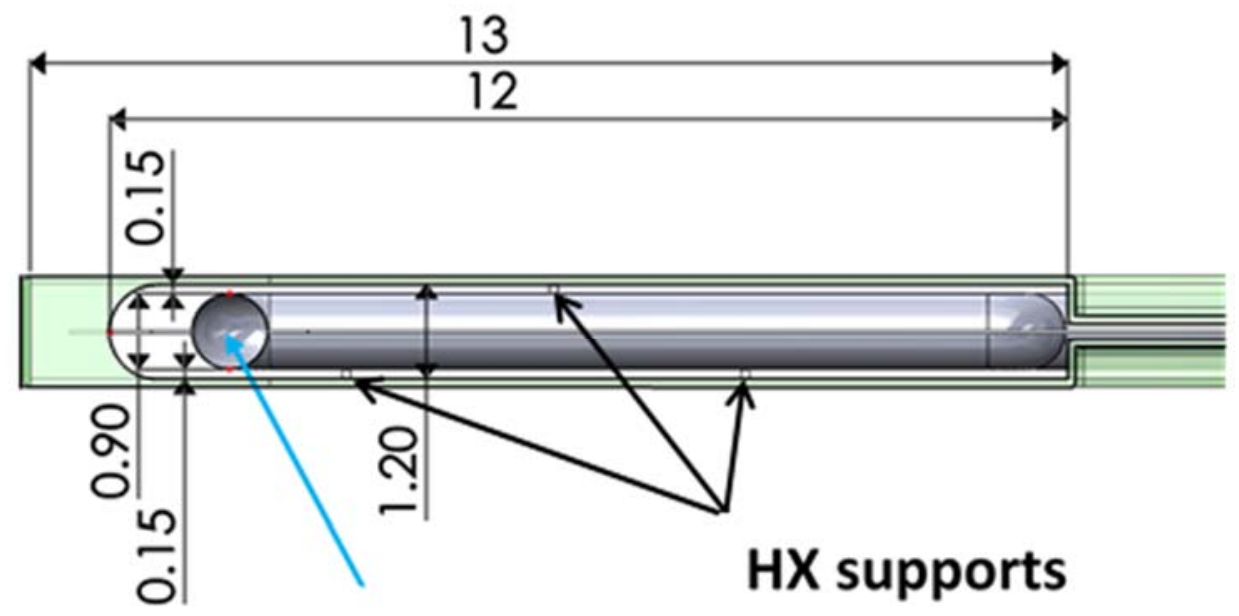

Water entrance

(c)

Fig. 3: Polymer heat exchanger: (a) unexpanded polymer heat exchanger core, (b) assembly of test section (expanded heat exchanger and header), (c) front view of the assembly (all dimensions in $\mathrm{cm}$ )

The fabricated polymer heat exchanger is shown in Fig. 4. The expanded polymer heat exchanger is shown in Fig. 4(a), while the assembled polymer heat exchanger with the headers is shown in Fig. 4(b). A second 
header with internal flow straighteners was added to the first header to create uniform air flow distribution Fig. 4(b).

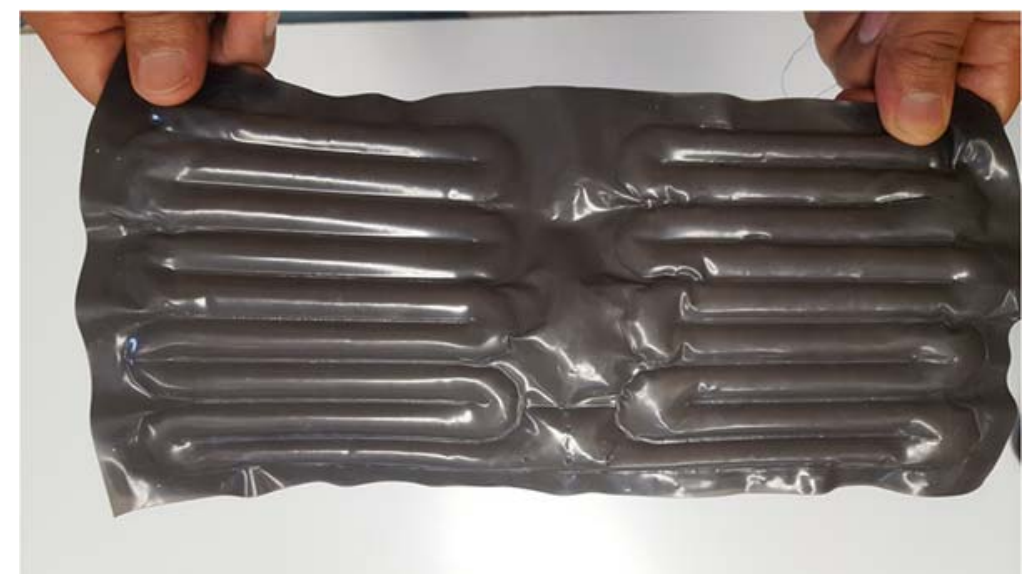

(a)

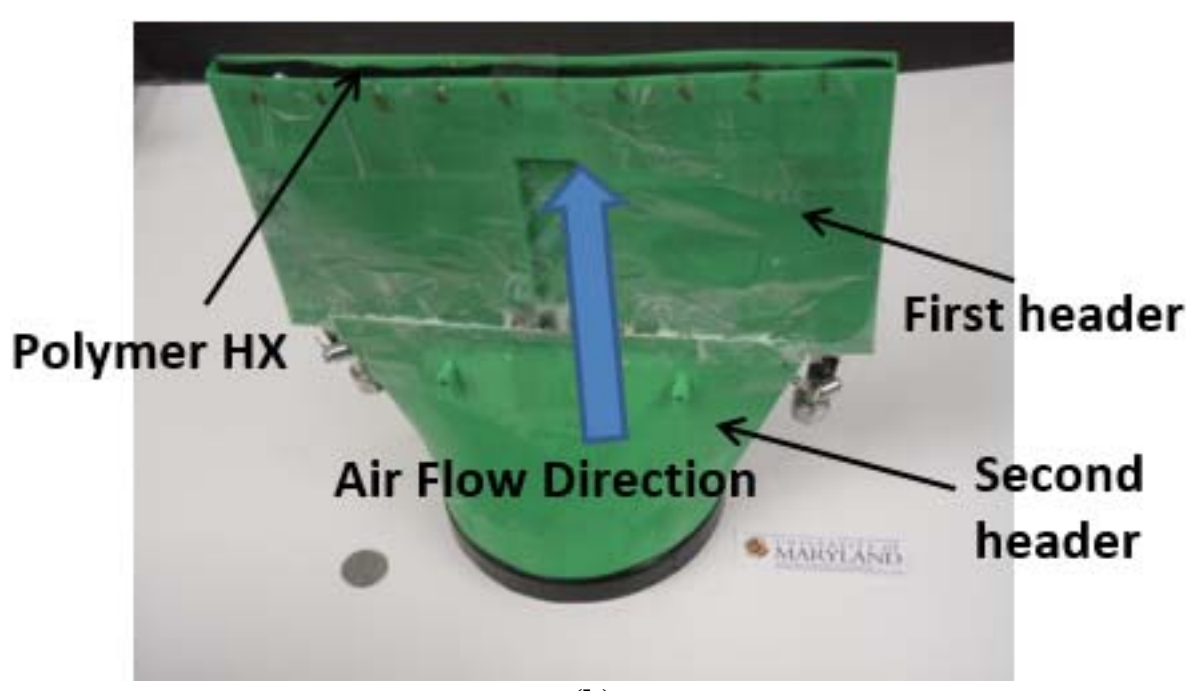

(b)

Fig. 4: Fabricated polymer heat exchanger: (a) expanded core unit, (b) assembled test section

\section{Experimental Test Setup}

The schematic diagram of the experimental test setup is shown in Fig. 5. The air-side flow path consists of an open loop with a heat exchanger to control the air temperature, a blower to drive the flow, and a flow meter to measure the flow rate. The polymer heat exchanger is installed at one end of the loop as shown in Fig. 6. In order to control the flow rate of the blower, a variable speed controller (VSC) was used. The water-side flow path consists of a closed loop with a chiller to control the water temperature and a Coriolis flow meter to measure the water flow rate. For performance evaluation, differential pressure transducers 
and thermocouples were used to measure both sides' pressure drop and temperature, respectively. Due to very low temperature differences (between 0.5 and $1.5^{\circ} \mathrm{C}$ ) in the inlet and the outlet of the water-side, a thermopile was used to measure the differential temperature across the inlet and the outlet of the water. Data were collected using a data acquisition system (DAQ).

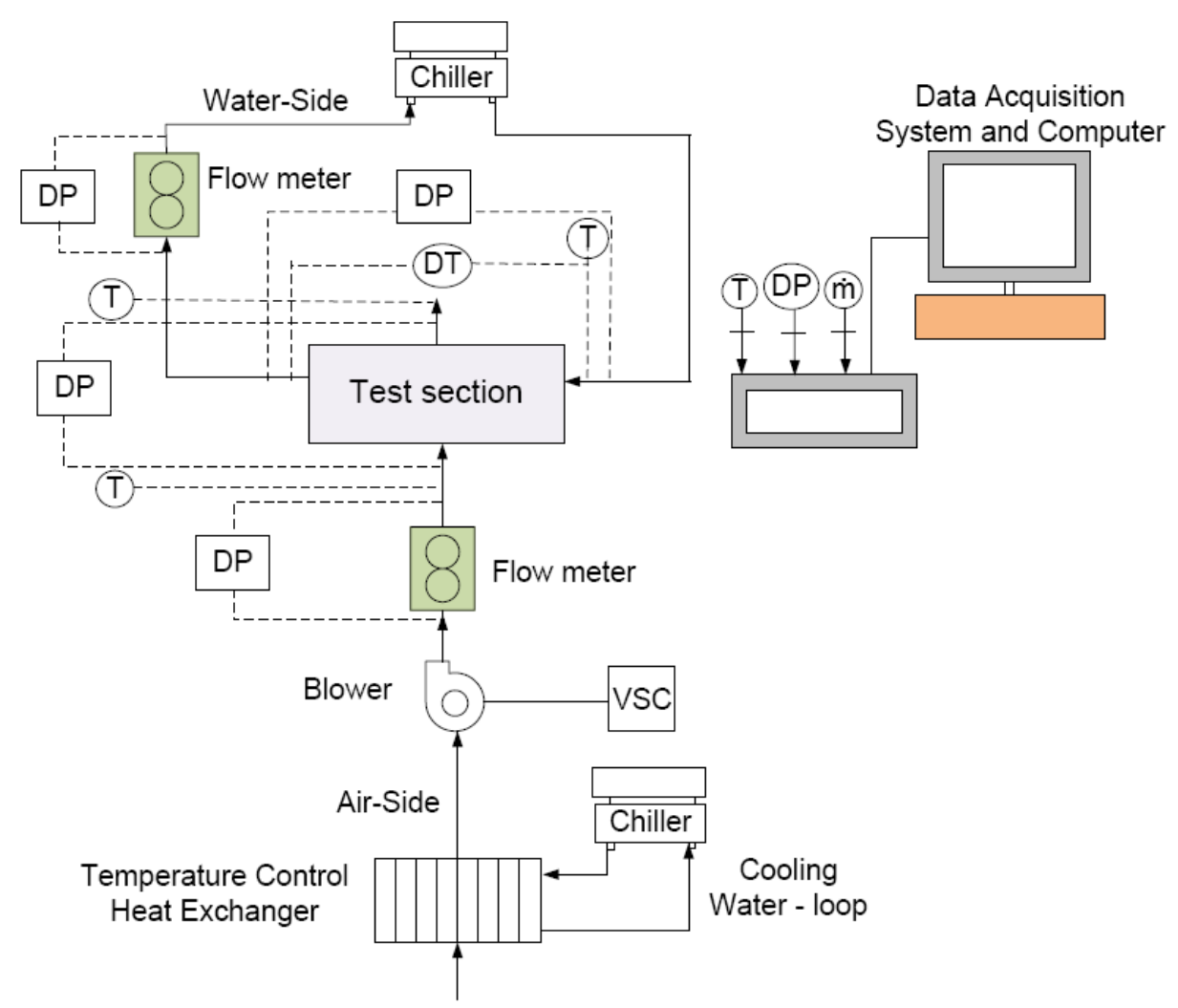

Fig. 5: Experimental setup schematic diagram 


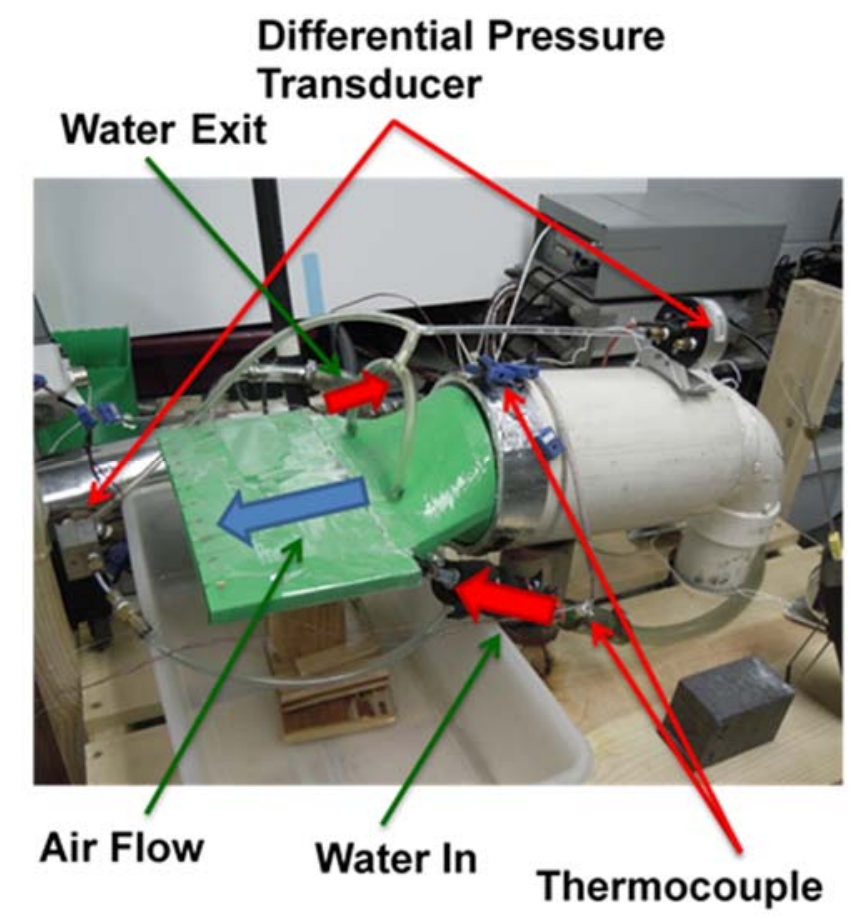

Fig. 6: Zoom-in view of the test section

\section{Experimental Procedure and Data Reduction}

The experiments were performed for the conditions shown in Table 1. Inlet air and water temperatures were fixed at $22.5{ }^{\circ} \mathrm{C}$ and $50{ }^{\circ} \mathrm{C}$, respectively. The experiments were run for varying air-side and water-side flow rates. Air side volumetric flow rate $\left(\dot{V}_{\text {air }}\right)$ was varied from $3 \mathrm{~L} / \mathrm{s}$ to $24 \mathrm{~L} / \mathrm{s}$ while keeping water volumetric flow rate $\left(\dot{V}_{\text {water }}\right)$ constant at $12.5 \mathrm{~mL} / \mathrm{s}$. Similarly, water-side volumetric flow rate was varied between 7 $\mathrm{mL} / \mathrm{s}$ to $21 \mathrm{~mL} / \mathrm{s}$ while keeping the airside volumetric flow rate constant at $20 \mathrm{~L} / \mathrm{s}$. In these experiments airside inlet and exit temperatures $\left(T_{\text {in,air }}\right.$ and $\left.T_{\text {out,air }}\right)$, air-side pressure drop $\left(\Delta p_{\text {air }}\right)$, water-side pressure drop $\left(\Delta p_{\text {water }}\right)$, water-side inlet temperature $\left(T_{\text {in,water }}\right)$, temperature difference between water inlet and outlet $\left(\Delta T_{\text {water }}\right)$, and air-side and water-side mass flow rate $\left(\dot{m}_{\text {air }}\right.$ and $\left.\dot{m}_{\text {water }}\right)$ were recorded for each case. 
Table 1: Experimental conditions

\begin{tabular}{cc}
\hline \multicolumn{2}{c}{ Temperature Boundary Conditions } \\
\hline$T_{\text {in,air }}$ & $22.5^{\circ} \mathrm{C}$ \\
$T_{\text {in,water }}$ & $50^{\circ} \mathrm{C}$ \\
\hline Flow Rate Boundary Conditions & (Variable air flow rate tests) \\
\hline$\dot{V}_{\text {water }}$ & $12.5 \mathrm{~mL} / \mathrm{s}$ \\
$\dot{V}_{\text {air }}$ & $3-24 \mathrm{~L} / \mathrm{s}$ \\
\hline Flow Rate Boundary Conditions (Variable water flow rate tests) \\
\hline$\dot{V}_{\text {water }}$ & $7-21 \mathrm{~mL} / \mathrm{s}$ \\
$\dot{V}_{\text {air }}$ & $20 \mathrm{~L} / \mathrm{s}$ \\
\hline
\end{tabular}

The heat exchanger's heat duty $(Q)$, overall heat transfer coefficient $(U)$, and air-side heat transfer coefficient $\left(h_{\text {air }}\right)$ were calculated to evaluate its performance. The heat duty was evaluated on both the air and water sides as shown in Eqs. (1) and (2). The energy balance between both sides was found to be within $1-24 \%$ of each other. The average of air-side and water-side heat duties (Eq. (3)) is used for further estimation of the heat transfer coefficients.

$$
\begin{gathered}
Q_{\text {air }}=\dot{m}_{\text {air }} c_{p, \text { air }}\left(T_{\text {out }, \text { air }}-T_{\text {in,air }}\right) \\
Q_{\text {water }}=\dot{m}_{\text {water }} c_{p, \text { water }}\left(T_{\text {in,water }}-T_{\text {out,water }}\right) \\
Q=0.5\left(Q_{\text {air }}+Q_{\text {water }}\right)
\end{gathered}
$$

In order to evaluate the overall heat transfer coefficient, the heat exchanger was divided into 18 numbers of identical segments as shown in Fig. 7. Flow configuration in each of the segments is cross flow. Before evaluating the overall heat transfer coefficient, the heat exchanger effectiveness in each segment needs to be calculated first.

Heat exchanger effectiveness $\left(\varepsilon_{H X}\right)$ is defined as the ratio between heat duty over the minimum of the heat capacity $(C)$ of the two fluids time the temperature difference between the two fluids $\left(\varepsilon_{H X}=\right.$ $\left.\frac{Q}{\min \left(C_{\text {hot }}, C_{\text {cold }}\right)\left(T_{\text {hot,in }}-T_{\text {cold }, \text { in }}\right)}\right)$. Bergman et al. has shown that for any heat exchanger, the effectiveness depends on the fluid's mass flow rate, overall heat transfer coefficient, area, and heat exchanger 
configuration [38]. As each one of the 18 segments is identical in geometry, mass flow rate input, and heat exchanger configuration (cross flow), heat exchanger effectiveness in each segment is same. The fluid properties are assumed to be constant for the flow conditions used in this experiment. As a result, the heat exchanger segment effectiveness $\left(\varepsilon_{H X, s e g}\right)$ can be derived as a function of known information of the airside and water-side inlet temperatures, mass flow rates of air and water, and the heat duty as shown in Eqs. (4)-(7) below:

$$
\begin{gathered}
Q_{i}=\dot{m}_{\text {water }} c_{p, \text { water }}\left(T_{\text {water }, \text { in }, i}-T_{\text {water }, \text { out }, i}\right) \text { for } i=1: 18 \\
Q_{i}=\frac{\dot{m}_{\text {air }}}{2} c_{p, \text { air }}\left(T_{\text {air }, \text { out }, i}-T_{\text {air }, \text { in }, i}\right) \text { for } i=1: 18 \\
\varepsilon_{H X, \text { seg }}=\frac{Q_{i}}{\min \left(C_{\text {water }}, C_{\text {air }}\right)\left(T_{\text {water }, i n, i}-T_{\text {air }, \text { }, i}\right)} \text { for } i=1: 18 \\
Q=\sum_{i=1}^{18} Q_{i}
\end{gathered}
$$

where $Q_{i}$ is the heat duty of each segment, $C$ is heat capacity derived as $C_{w a t e r}=\dot{m}_{w a t e r} C_{p, w a t e r}$, and $C_{\text {air }}=\frac{\dot{m}_{\text {air }}}{2} c_{p, \text { air }}$, as only half of air flow rate passes over each segment as shown in Fig. 7. 


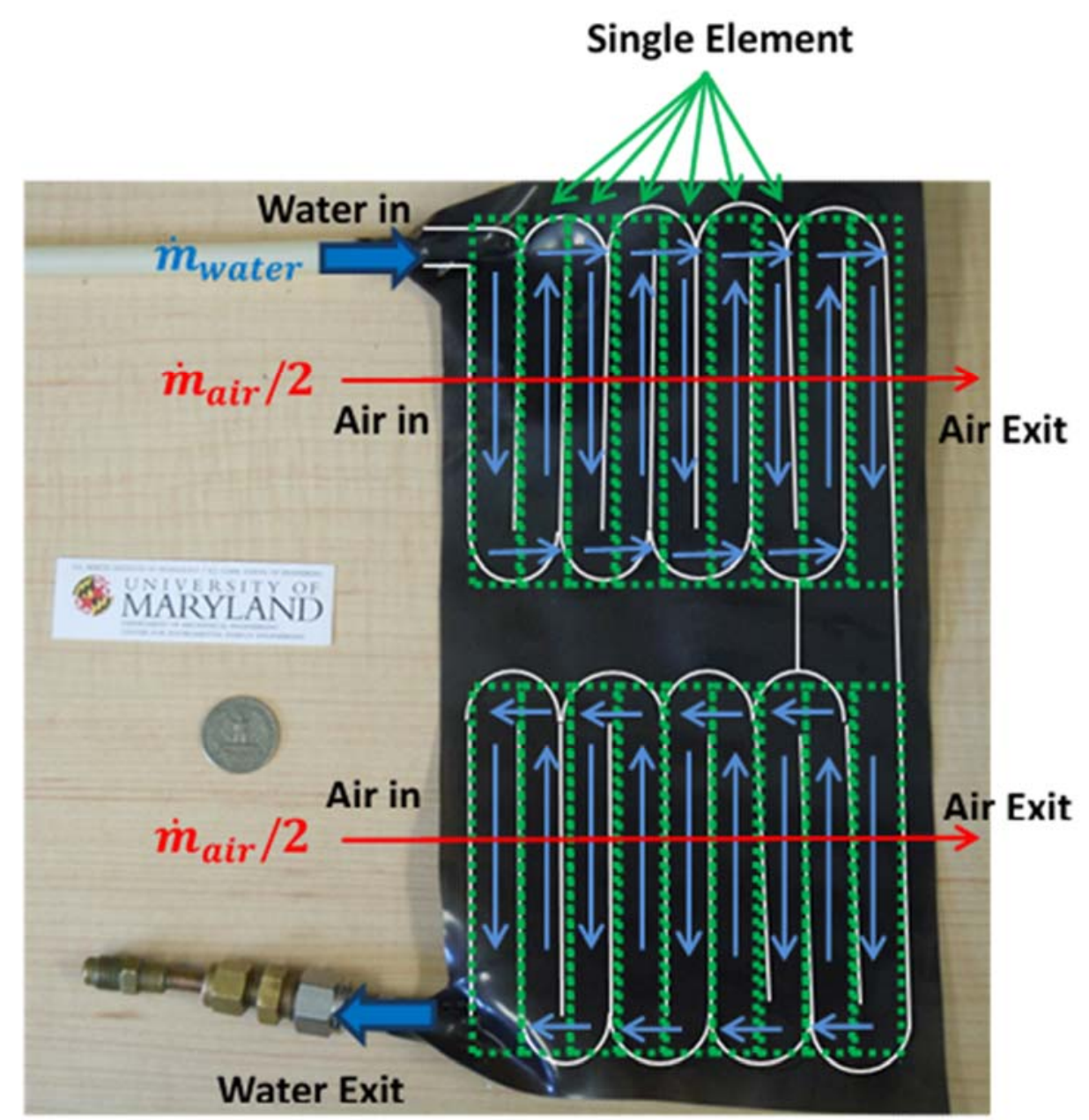

Fig. 7: Polymer heat exchanger computational domain showing the segments

Considering the symmetric geometry of the heat exchanger and the similar flow conditions (both air-side and water-side) for all the segments, the overall heat transfer coefficient $(U)$ of the entire heat exchanger can be assumed as equivalent to the overall heat transfer coefficient in each segment. The overall heat transfer coefficient can be evaluated using the unmixed cross flow NTU method as shown in Eqs. (8) and (9) below as a function of air-side and water-side mass flow rates and heat exchanger segment effectiveness as defined in Ref. [38].

$$
\begin{gathered}
U=\frac{N T U \times \min \left(C_{\text {water }}, C_{\text {air }}\right)}{A_{H, \text { seg }}} \\
\varepsilon_{H X, \text { seg }}=1-\exp \left[\left(1 / C_{r}\right) N T U^{0.22}\left\{\exp \left[-C_{r}(N T U)^{0.78}\right]-1\right\}\right]
\end{gathered}
$$


where $A_{H, s e g}$ is heat transfer area per segment, which was calculated as $28.8 \mathrm{~cm}^{2}$, and $C_{r}=\frac{\min \left(C_{w a t e r}, C_{\text {air }}\right)}{\max \left(C_{w a t e r}, C_{\text {air }}\right)}$.

Air side heat transfer coefficient can then be calculated from Eqs. (10)-(14):

$$
\begin{gathered}
\frac{1}{U A_{H, \text { seg }}}=R_{\text {tot }} \\
R_{\text {tot }}=R_{\text {air }}+R_{\text {wall }}+R_{\text {water }} \\
R_{\text {air }}=\frac{1}{h_{\text {air }} A_{H, \text { seg }}} \\
R_{\text {wall }}=\frac{\ln \left(\frac{r_{\text {out }}}{r_{\text {in }}}\right)}{2 \pi L_{\text {water }, \text { seg }} k} \\
R_{\text {water }}=\frac{1}{h_{\text {water }} A_{H, s e g}}
\end{gathered}
$$

where $R$ is thermal resistance, $r_{\text {out }}$ and $r_{\text {in }}$ is the channel outer and inner radius, $L_{\text {water,seg }}$ is the water flow length per segment (calculated as $9 \mathrm{~cm})$, and $k$ is the HDPE thermal conductivity $(k=0.5 \mathrm{~W} / \mathrm{mK})$. As the polymer layer is only $0.15 \mathrm{~mm}$ thick, air-side and water-side heat transfer areas can be assumed to be the same and defined as $A_{H, \text { seg }}$.

Water-side convective heat transfer coefficient $\left(h_{\text {water }}\right)$ was calculated using the analytical solution for a circular channel described in Ref. [39] based on the assumption that the water-side channel is fully circular when the flow is applied. Although this is not the case for all flow rates, the assumption does not affect the overall heat transfer results. This is because the water-side thermal resistance is not the limiting factor of the air-water heat exchanger. A comparison of air-side, water-side and wall thermal resistances will be presented in the next section. Air-side heat transfer coefficient can be calculated by using Eqs. (10)-(14).

\section{Uncertainty Analysis}

Uncertainty propagation analysis was performed to calculate the inaccuracy in the heat exchanger performance $(Q, h, U, \Delta p)$ due to inaccuracy in the measurements. A list of the measurement equipment is shown in Table 2 with the corresponding accuracies. Based on the method explained in NIST Technical 
Note 1297 [40], the uncertainty of calculated quantity $Y\left(U_{Y}\right)$ which is a function of $X_{1}, X_{2}, \ldots, X_{N}$ with uncertainty of $U_{X_{1}}, U_{X_{2}}, \ldots, U_{X_{N}}$ can be calculated as:

$$
U_{Y}=\sqrt{\sum_{i}\left(\frac{\partial Y}{\partial X_{i}}\right)^{2} U_{X_{i}}^{2}}
$$

Using this method, the uncertainties for all heat exchanger performance parameters $(Q, h, U, \Delta p)$ were calculated, and the error bars are included in the results presented in the next sections.

Table 2: List of measurement equipment and its accuracy

\begin{tabular}{ccc}
\hline Equipment Function & Equipment Name & Accuracy \\
\hline Air-side flow rate & $\begin{array}{c}\text { Fischer Porter F Rotameter } \\
\text { (Model\#: 10A4557SS) }\end{array}$ & $\pm 2 \%$ \\
Water-side flow rate & $\begin{array}{c}\text { FCI FlexCor mass flowmeter compact } \\
\text { (Model\#: CMF-CNQOAOAID-C00000) }\end{array}$ & $\pm 1 \%$ \\
Temperature & T type thermocouple & $\pm 0.5^{\circ} \mathrm{C}$ \\
Air-side pressure drop & Setra pressure transducer & $0.14 \% \mathrm{FS}$ of 5 inch H20 \\
Water-side pressure drop & (Model\#: 239) & $0.25 \% \mathrm{FS}$ of 35 $\mathrm{kPa}$ \\
& Validyne P55 general purpose pressure & \\
& transducer & \\
& (Model\#: P55D 4-N-1-36-S-4-S) & \\
\hline
\end{tabular}

\section{Experimental Results and Discussions}

\subsection{Heat Transfer Performance}

The heat transfer performance of the polymer heat exchanger for a constant water flow rate is shown in Fig. 8. The results are plotted as functions of air-side volumetric flow rate and Reynolds number $\left(R e_{\text {air }}\right) . R e_{\text {air }}$ is defined as:

$$
R e_{\text {air }}=\frac{D_{\text {air }} \dot{m}_{\text {air }} / 2}{A_{\text {front }, \text { air }} \mu_{\text {air }}}
$$

where $A_{\text {front,air }}$ is air-side frontal area evaluated as the frontal area of the header as shown in Fig. 3(c) $\left(A_{\text {front }, \text { air }}=0.13 \mathrm{~m} \times 0.012 \mathrm{~m}\right)$ and $D_{\text {air }}$ is air-side hydraulic diameter also evaluated at the frontal area 
of the header $\left(D_{\text {air }}=0.022 \mathrm{~m}\right)$. It should be noted that the air-side mass flow rate is divided by two in the above equation. This is because the heat exchanger consists of two identical sections as shown in Fig. 7.

Fig. 8(a) shows the heat duty of the polymer heat exchanger at $27.5^{\circ} \mathrm{C}$ temperature difference between inlet air and inlet water. The graph shows that up to $225 \mathrm{~W}$ heat duty is possible. The air-side heat transfer coefficient is evaluated between 35 to $135 \mathrm{~W} / \mathrm{m}^{2} \mathrm{~K}$ as shown in Fig. 8(b). The overall heat transfer coefficient of the polymer heat exchanger is in the range of $35-120 \mathrm{~W} / \mathrm{m}^{2} \mathrm{~K}$ as shown in Fig. 8(c). This number is higher than typical a finned-tube heat exchanger's overall heat transfer coefficient, which is typically in the range of $25-50 \mathrm{~W} / \mathrm{m}^{2} \mathrm{~K}$ [38]. Analyzing the trend, as expected, heat duty, air-side heat transfer coefficient, and overall heat transfer coefficient are increasing with increase in air-side Reynolds number. Another observation is that the overall heat transfer coefficient is close to the air-side heat transfer coefficient. This in turn suggests that the water-side thermal resistance as well as the wall thermal resistances are less influential than the air-side thermal resistance (see further discussion on the thermal resistances later in this section).

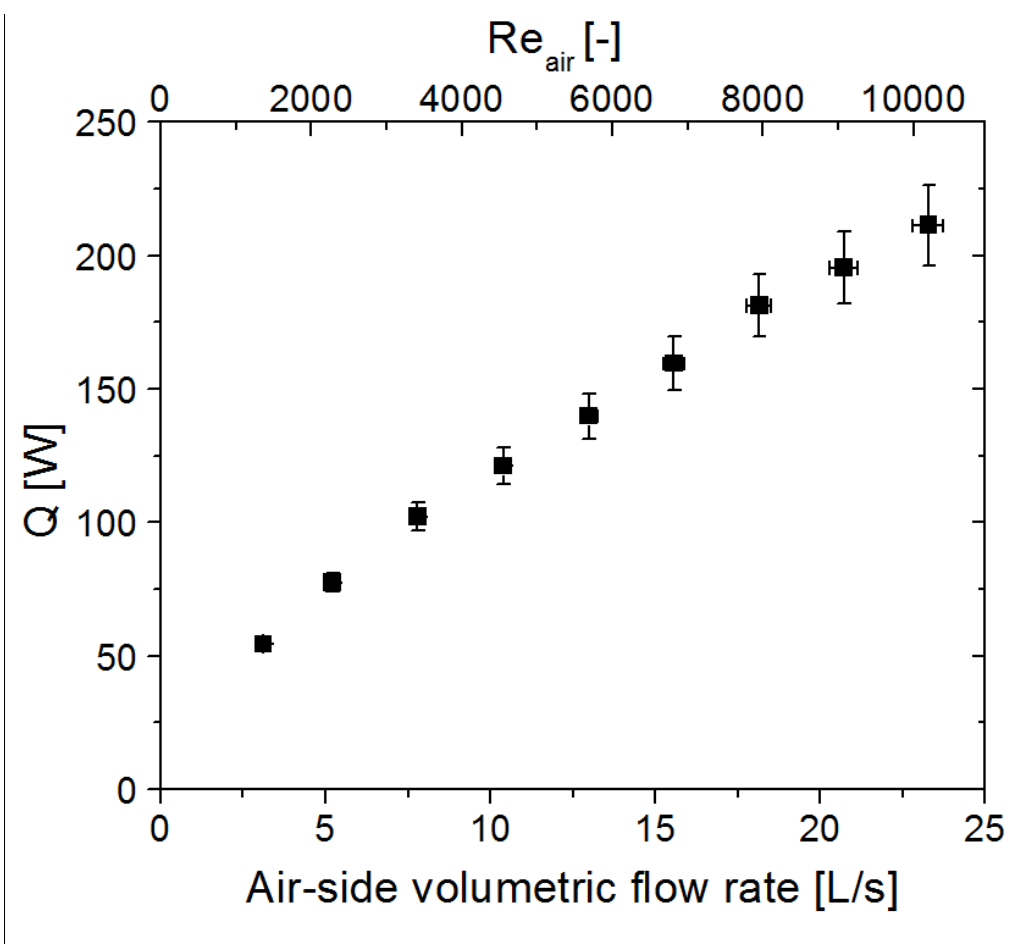

(a) 


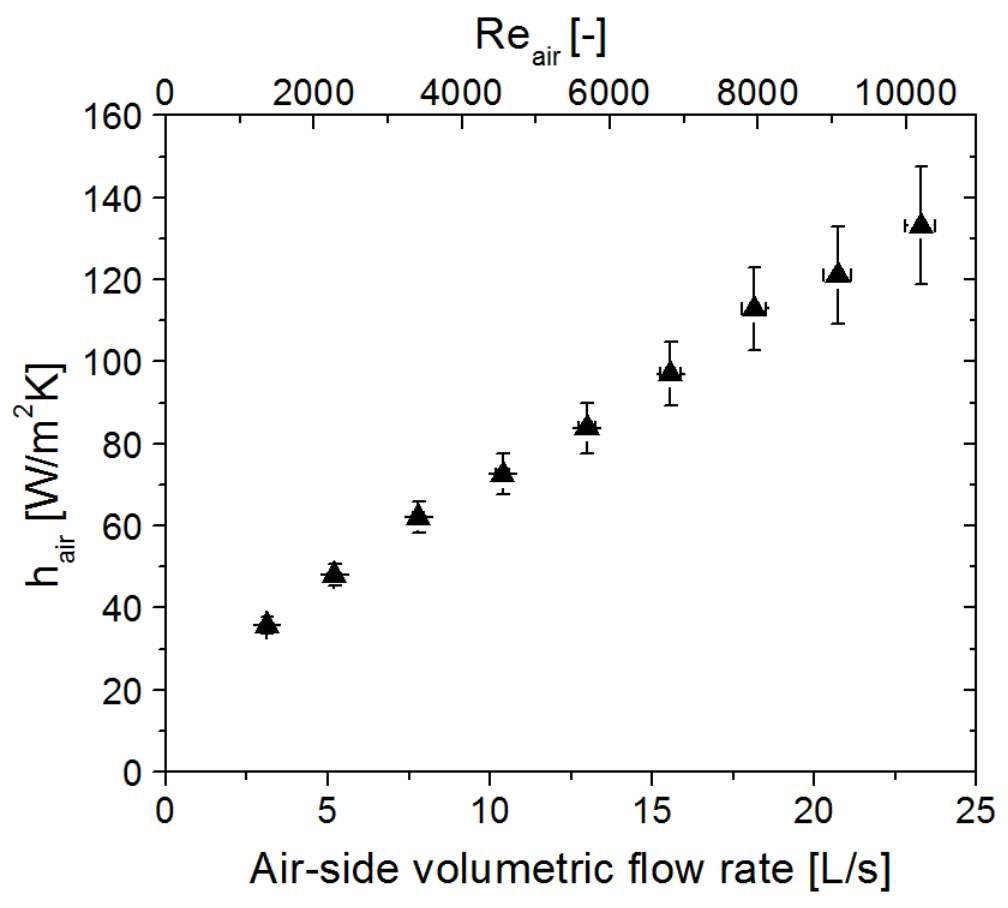

(b)

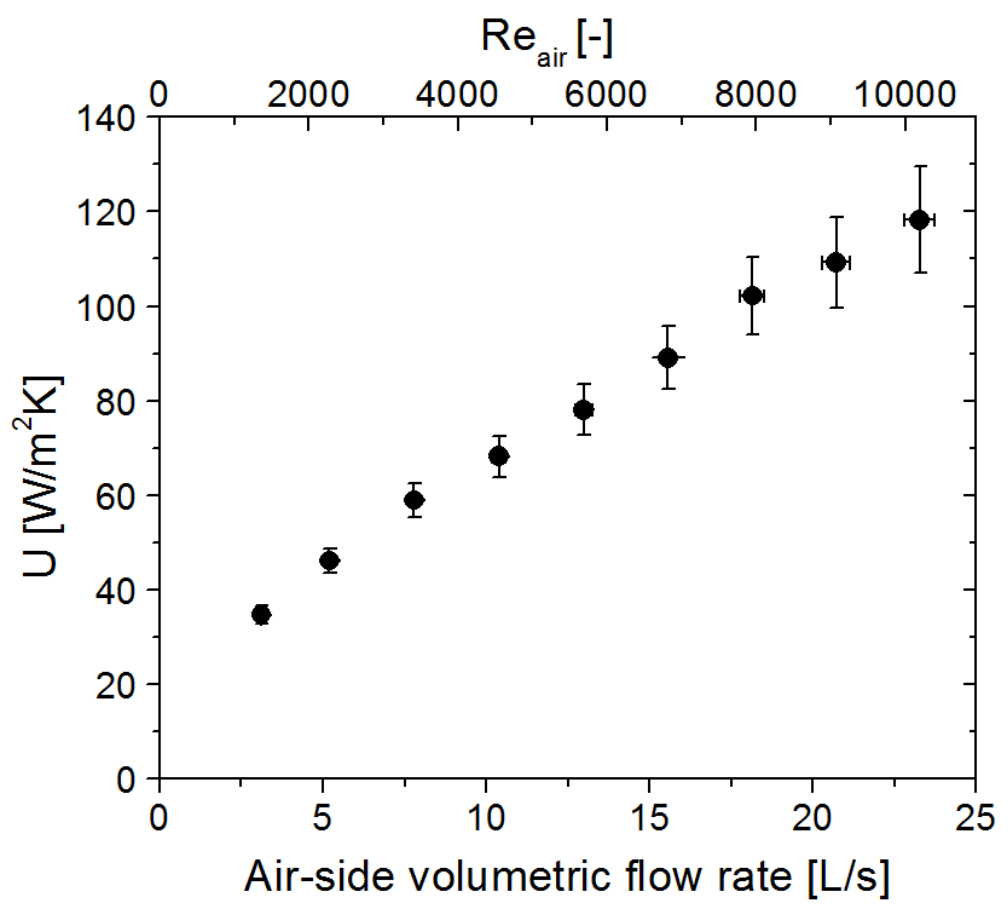

(c)

Fig. 8: Heat transfer performance for varying air flow rate and constant water flow rate of $12.5 \mathrm{~mL} / \mathrm{s}$ : (a) Heat duty, (b) air-side heat transfer coefficient, (c) overall heat transfer coefficient 
Similarly, the heat transfer performance results for the polymer heat exchanger for varying water side flow rate and nominal Reynolds number are shown in Fig. 9. Nominal Reynolds number $\left(R e_{n o m, w a t e r}\right)$ is calculated based on assuming a fully circular water tube and given as:

$$
R e_{\text {nom,water }}=\frac{D_{\text {water }} \dot{m}_{\text {water }}}{A_{\text {front }, \text { water }} \mu_{\text {water }}}
$$

where $D_{\text {water }}$ and $A_{\text {front,water }}$ are water-side hydraulic diameter and frontal area with corresponding values of $0.87 \mathrm{~cm}$ and $0.59 \mathrm{~cm}^{2}$, respectively.

The heat transfer performance of the polymer heat exchanger for a constant air flow rate is shown in Fig. 9. There is a slight increasing trend in overall heat transfer coefficient as the water flow rate increases. However, the overall heat transfer coefficient is not significantly dependent on the water-side flow rate. This shows that the water-side thermal resistance is only contributing a small portion of the total thermal resistance.

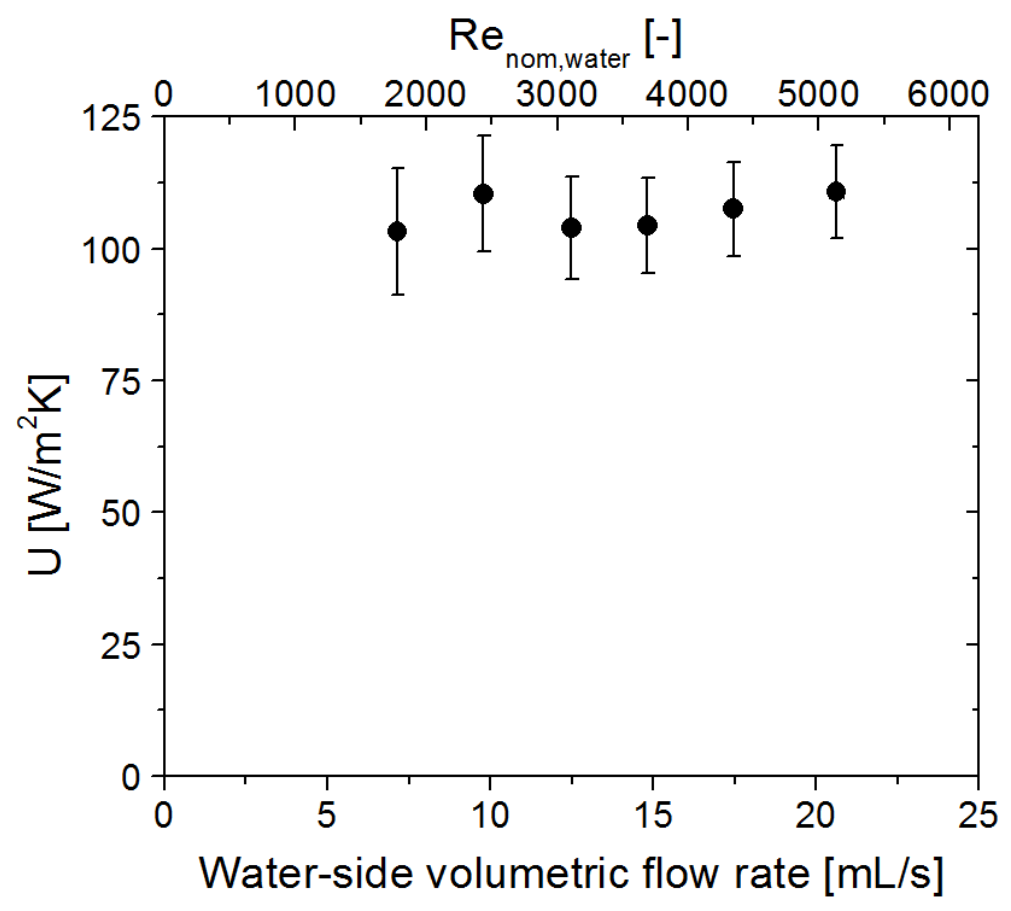

Fig. 9: Overall heat transfer coefficient vs. water flow rate and Reynolds number (constant air volume flow rate of $20 \mathrm{~L} / \mathrm{s})$ 
The percentage distribution of the thermal resistance (evaluated from Eqs. (11)-(14)) for three different airside Reynolds numbers is shown in Fig. 10.These are based on the minimum, middle value, and maximum air-side flow rates set during the experiment. The water-side flow rate is the same for all three cases $(12.5 \mathrm{~mL} / \mathrm{s})$. As can be seen in the figure, despite being built out of low thermal conductivity material, the wall thermal resistance is very low (max $3 \%$ ) as compared to the air-side thermal resistance, which is the dominant resistance in all three cases. This shows that the thickness of the heat exchanger can be further increased for higher pressure heat exchangers without significantly changing the thermal performance of the heat exchanger.

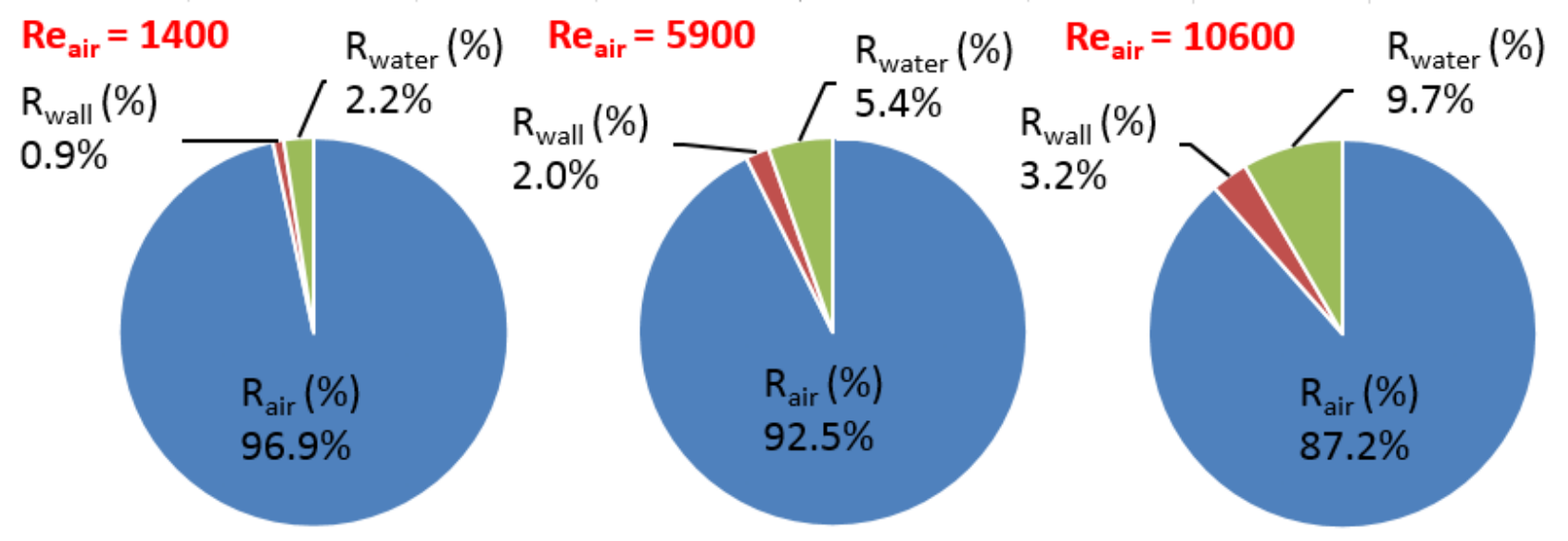

Fig. 10: Distribution of the thermal resistances for 3 different air-side Reynolds numbers (all cases evaluated at the same water flow rate of $12.5 \mathrm{~mL} / \mathrm{s}$ )

\subsection{Pressure Drop Performance}

Air-side pressure drop performances as a function of air-side Reynolds number for three different water flow rates are shown in Fig. 11. The trend is as expected where pressure drop increases with air-side Reynolds number. Interestingly, it was found that the air-side pressure drop slightly increased as water-side flow rate was increased. This was because when water side flow rate was increased, the water channels started to expand further, restricting the airflow path. At water-side volumetric flow rate of $12.5 \mathrm{~mL} / \mathrm{s}$, the air-side pressure drop was in the range of 13-530 Pa. Since the air side pressure transducer used for the 
experiment has very high accuracy, with uncertainty of only $1.74 \mathrm{~Pa}$, as listed in Table 2 , no noticeable uncertainty is seen in air-side pressure drop in Fig. 11.

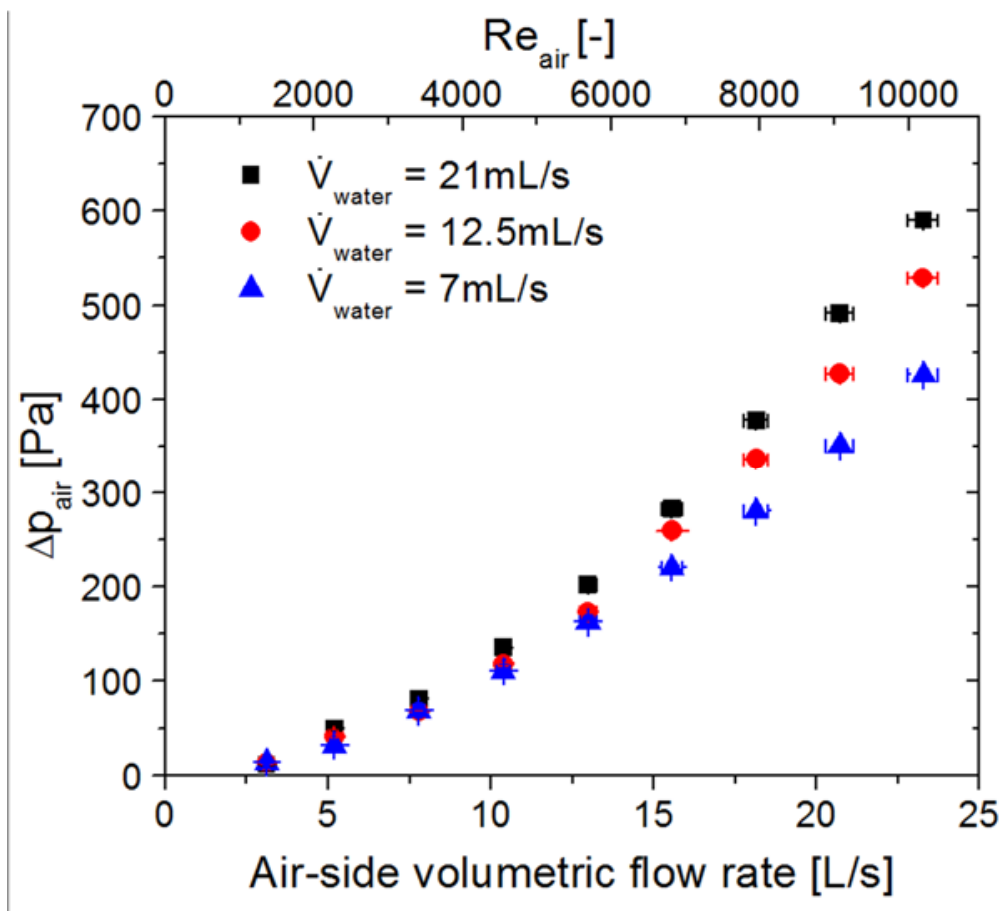

Fig. 11: Air-side pressure drop vs. air flow rate and Reynolds number

The water-side pressure drop result is shown in Fig. 12. Pressure drop shows an increasing trend as waterside flow rate increases. This variation was attributed to deformation of water tubes as the water flow rate increased. Numerical analysis of water flow in an elliptical pipe was performed for different values of the ratio of major to minor axes of the ellipse $(S)$ where $S=1$ corresponds to a circle. Experimental results matched the numerical values of pressure drop at $S=0.4$ for low flow rates; however, the experimental results were closer to the numerical values at $S=0.5$ at higher flow rates. This shows that the water-side pressure drop is closer to elliptical pipe performance rather than circular pipe performance. It should be noted that the actual hydraulic diameter decreases as the value of $S$ decreases. The hydraulic diameter varied from $0.87 \mathrm{~cm}$ to $0.62 \mathrm{~cm}$ as $S$ varied from 1 to 0.4 . While the elliptical tube is one reason for the high waterside pressure drop, there is also another factor than can cause higher water-side pressure drop. Some 
bending was noted in the water channels as shown in Fig. 4(a). This bending can cause additional pressure drop.

Although the water-side pressure drop results show that the actual water channel is an ellipse, our assumption on using a circular channel analytical solution to evaluate the water-side heat transfer coefficient can still be justified, as the thermal resistance in the air side is much more dominant than on the water side as shown in Fig. 10. As a result, minor changes in water-side heat transfer coefficient will not significantly affect the overall heat transfer performance. This was confirmed by recalculating the waterside heat transfer coefficient for elliptical pipe $(S=0.5)$. The air-side heat transfer coefficient was reevaluated and found to decrease by maximum $2 \%$.

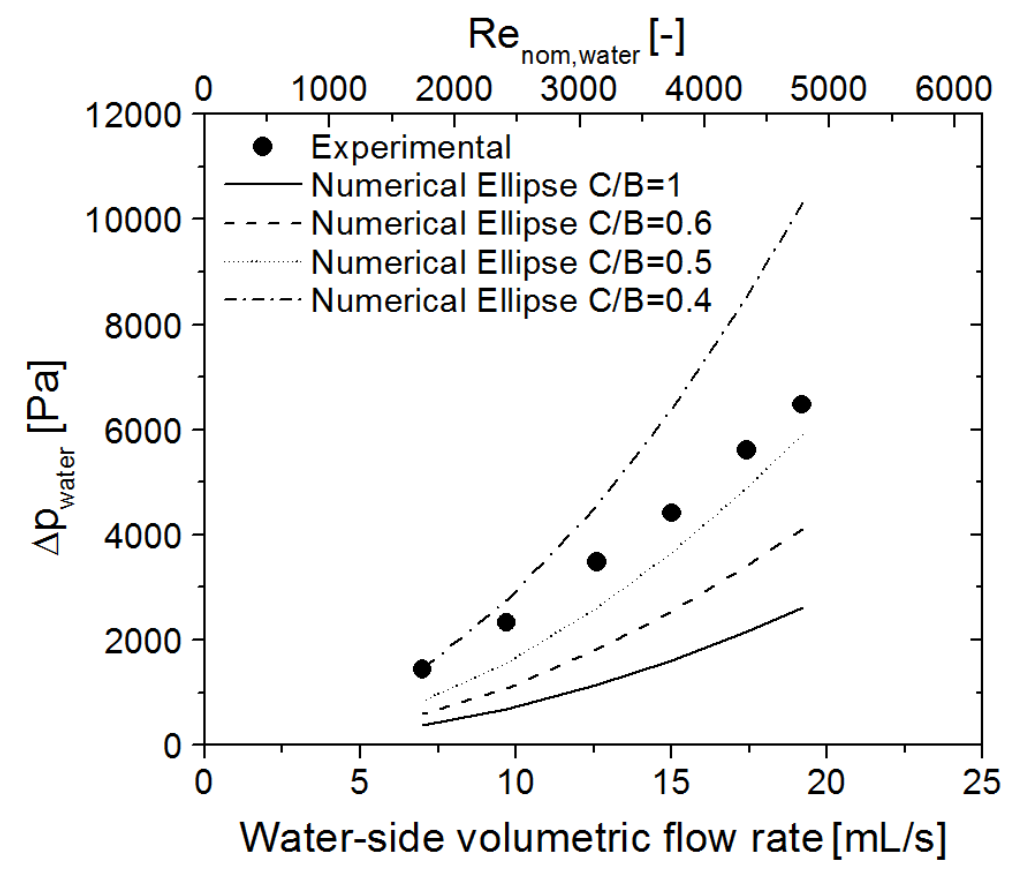

Fig. 12: Water-side pressure drop vs. water flow rate and Reynolds number

\subsection{Pressure Containment Test}

In order to evaluate the strength of the polymer heat exchanger, a destructive pressure containment test was performed. The pressure was slowly increased in 1 psi increments until the heat exchanger started to leak at one of the joining points. The failure pressure was recorded as $28 \mathrm{psig}$ ( 2 bars $)$. The current polymer heat exchangers is designed for dry cooling of thermoelectric power plant with an operation gauge pressures up 
to 2 bars. However, considering the fact that the polymer wall thermal resistance is only $1-3 \%$ of the overall thermal resistance, the wall thickness can be somewhat increased without compromising the thermal performance of the heat exchanger significantly. Using smaller channel geometries combined with higher wall thicknesses, the line welded polymer heat exchangers may be used for low to moderate operating pressure applications.

\subsection{Comparison with Conventional Technology}

Air-side performance of the polymer heat exchanger was compared with the performance of five commonly used, commercially available metallic plain plate fin heat exchanger surfaces. The plain plate fin surface performances (pressure drop and heat transfer coefficient) were calculated based on the friction factor and Colburn j-factor test data provided by Kays and London [41]. The flow lengths for all five plain plate fin heat exchangers were kept the same as the polymer heat exchanger air flow length of $0.11 \mathrm{~m}$ as shown in Fig. 3(b). The geometries for all five plain plate fin surfaces are listed in Table 3. For more detailed dimension specifications please refer to Ref. [41].

Table 3: Plain plate fin surface geometries [41]

\begin{tabular}{|c|c|c|}
\hline & Fin Pitch (fin/cm) & Plate Spacing (cm) \\
\hline Plain Plate Fin 1 & 7.8 & 0.635 \\
\hline Plain Plate Fin 2 & 4.4 & 0.635 \\
\hline Plain Plate Fin 3 & 5.9 & 1.06 \\
\hline Plain Plate Fin 4 & 4.0 & 1.38 \\
\hline Plain Plate Fin 5 & 5.8 & 8.38 \\
\hline
\end{tabular}

The performance comparison of the polymer heat exchanger with plain plate fin heat exchangers is shown in Fig. 13. The performance of the polymer heat exchanger is equal or even superior to some of the plain plate fin heat exchangers performance. This shows that polymer heat exchangers show promise in competing with conventional metallic heat exchangers in term of heat transfer performance. In addition, the lower weight, lower cost, and antifouling and anticorrosion properties of polymer heat exchangers are major advantages over conventional metallic heat exchangers. 


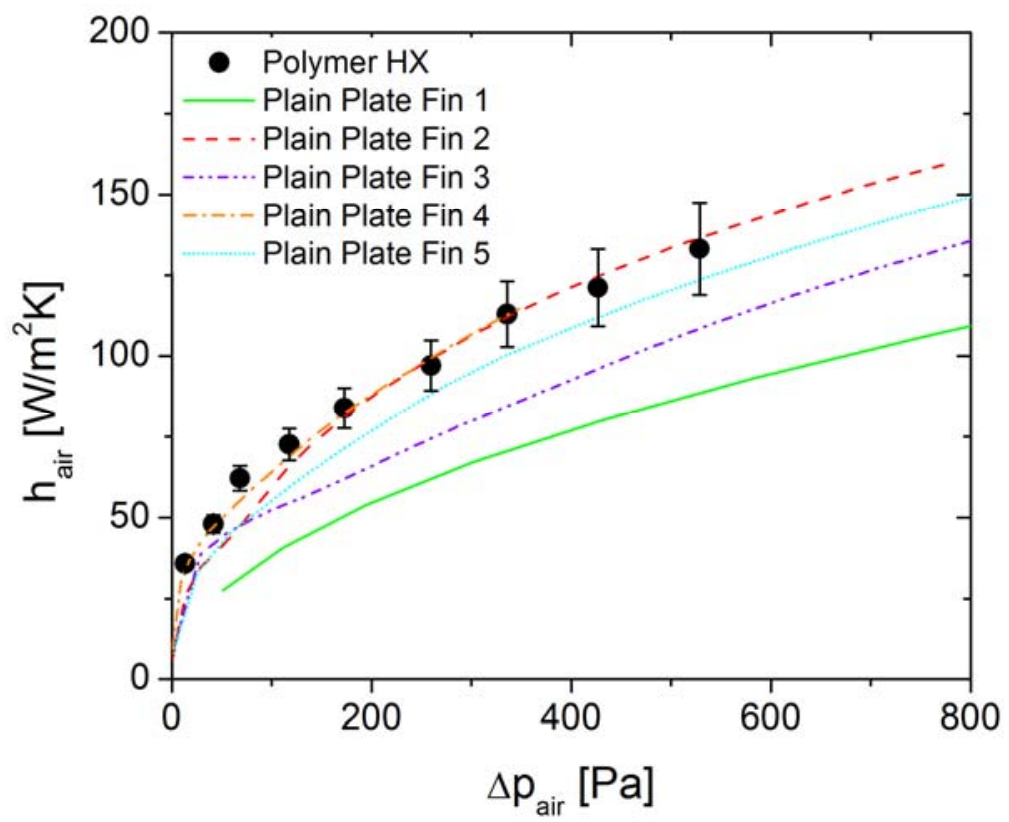

Fig. 13: Performance comparison of the polymer heat exchanger with plain plate fin heat exchangers

\section{Conclusions}

In this work a cost effective air-to-water polymer heat exchanger utilizing prime surface design approach was successfully fabricated by layer-by-layer line laser welded additive manufacturing out of high density polyethylene sheets and experimentally tested. Experimental tests of the heat exchanger show that the overall heat transfer coefficient of $35-120 \mathrm{~W} / \mathrm{m}^{2} \mathrm{~K}$ is achievable for air-side flow rate of $3-24 \mathrm{~L} / \mathrm{s}$ and waterside flow rate of $12.5 \mathrm{~mL} / \mathrm{s}$. The air-side heat transfer coefficient were evaluated on the range of 35-120 $\mathrm{W} / \mathrm{m}^{2} \mathrm{~K}$. Compared to commercially available plain plate fin surfaces, polymer heat exchanger offers equal or superior heat transfer coefficient performance for the same pressure drop. The results also show that wall thermal resistance is not a liming factor for low thickness polymer heat exchanger. It only represents up to $3 \%$ of the total thermal resistance. Due to their advantage of low weight, low cost, antifouling and anticorrosion properties as compared to metallic heat exchangers, polymer heat exchangers are promising alternatives to conventional metallic heat exchangers for certain applications. 


\section{Acknowledgments}

Financial support of this work by US Department of Energy ARPA-E, Award \# DE-AR0000507 is greatly acknowledged. The views and opinions of authors expressed herein do not necessarily state or reflect those of the United States Government or any agency thereof. The authors would also like to acknowledge helpful discussions with Dr. David Denkenberger and Mr. Gerald Anzalone for technical assistance. Additionally, the authors wish to thank Dr. James Klausner and Mr. Geoffrey Short (both of ARPA-E) for their technical insight and discussions that favorably affected the design of our modules and the general approach to the problem.

\section{References}

[1] J. G. Cevallos, A. E. Bergles, A. Bar-Cohen, P. Rodgers, and S. K. Gupta, Polymer heat exchangershistory, opportunities, and challenges, Heat Transfer Engineering. 33(13) (2012), 1075-1093.

[2] D. C. Deisenroth, M. A. Arie, A. Shooshtari, S. Dessiatoun, and M. Ohadi, Review of most recent progress on development of polymer heat exchangers for thermal management applications, Proceeding ASME 2015 International Technical Conference and Exhibition on Packaging and Integration of Electronic and Photonic Microsystems InterPACK2015, San Francisco, CA, 2015.

[3] C. T'Joen, Y. Park, Q. Wang, A. Sommers, X. Han, and A. Jacobi, A review on polymer heat exchangers for HVAC\&R applications, International Journal of Refrigeration. 32(5) (2009), 763-779.

[4] L. Zaheed, and R. Jachuck, Review of polymer compact heat exchangers, with special emphasis on a polymer film unit, Applied Thermal Engineering. 24(16) (2004), 2323-2358.

[5] Z. Han, and A. Fina, Thermal conductivity of carbon nanotubes and their polymer nanocomposites: a review, Progress in Polymer Science. 36(7) (2011), 914-944.

[6] X. Wang, Z. Yong, Q. Li, P. D. Bradford, W. Liu, D. S. Tucker, W. Cai, H. Wang, F.-G. Yuan, and Y. Zhu, Ultrastrong, stiff and multifunctional carbon nanotube composites, Materials Research Letters. 1(1) (2013), 19-25.

[7] M. O. Khan, S. N. Leung, E. Chan, H. E. Naguib, F. Dawson, and V. Adinkrah, Effects of microsized and nanosized carbon fillers on the thermal and electrical properties of polyphenylene sulfide based composites, Polymer Engineering \& Science. 53(11) (2013), 2398-2406.

[8] N. Balachander, I. Seshadri, R. J. Mehta, L. S. Schadler, T. Borca-Tasciuc, P. Keblinski, and G.

Ramanath, Nanowire-filled polymer composites with ultrahigh thermal conductivity, Applied Physics Letters. 102(9) (2013), 093117.

[9] W. Zhou, C. Wang, T. Ai, K. Wu, F. Zhao, and H. Gu, A novel fiber-reinforced polyethylene composite with added silicon nitride particles for enhanced thermal conductivity, Composites Part A: Applied Science and Manufacturing. 40(6) (2009), 830-836.

[10] L. H. Sinh, J. M. Hong, B. T. Son, N. N. Trung, and J. Y. Bae, Thermal, dielectric, and rheological properties of aluminum nitride/liquid crystalline copoly (ester amide) composite for the application of thermal interface materials, Polymer Composites. 33(12) (2012), 2140-2146. 
[11] V. Morcos, and H. M. Shafey, Performance analysis of a plastic shell-and-tube heat exchanger, Journal of Elastomers and Plastics. 27(2) (1995), 200-213.

[12] W. Liu, J. Davidson, and S. Mantell, Thermal analysis of polymer heat exchangers for solar water heating: a case study, Journal of Solar Energy Engineering. 122(2) (2000), 84-91.

[13] Y. Wang, J. Davidson, and L. Francis, Scaling in polymer tubes and interpretation for use in solar water heating systems, Journal of Solar Energy Engineering. 127(1) (2005), pp. 3-14.

[14] D. M. Zarkadas, and K. K. Sirkar, Polymeric hollow fiber heat exchangers: An alternative for lower temperature applications, Industrial \& Engineering Chemistry Research. 43(25) (2004), 8093-8106.

[15] D. M. Zarkadas, B. Li, and K. K. Sirkar, Polymeric hollow fiber heat exchangers (PHFHEs): A new type of compact heat exchanger for lower temperature applications, Proc. Proceedings of the ASME Summer Heat Transfer Conference, San Francisco, CA, 2005, 429-438.

[16] L. Song, B. Li, D. Zarkadas, S. Christian, and K. K. Sirkar, Polymeric hollow-fiber heat exchangers for thermal desalination processes, Industrial \& Engineering Chemistry Research. 49(23) (2010), 1196111977.

[17] X. Yan, B. Li, B. Liu, J. Zhao, Y. Wang, and H. Li, Analysis of improved novel hollow fiber heat exchanger, Applied Thermal Engineering. 67(1) (2014), 114-121.

[18] Sirkar, K., Korikov, A., Kosaraju, P., and Zarkadas, D., Polymeric hollow fiber heat exchange systems, US Patent 20070107884 A1, 2007.

[19] Monoblock, Monoblock - The Polymer Heat Exchanger, http://www.segerfrojd.com/, (accessed December 2015)

[20] AIL Research, Inc., Plastic Interchange Heat Exchanger, http://ailr.com/our-technology/plasticinterchange-heat-exchanger/, (Accessed December 2015)

[21] J. Burns, and R. Jachuck, Condensation studies using cross-corrugated polymer film compact heat exchanger, Applied Thermal Engineering. 21(4) (2001), 495-510.

[22] L. Cheng, and C. W. V. D. Geld, Experimental study of heat transfer and pressure drop characteristics of air/water and air-steam/water heat exchange in a polymer compact heat exchanger, Heat Transfer Engineering. 26(2) (2005), 18-27.

[23] C. Harris, K. Kelly, T. Wang, A. McCandless, and S. Motakef, Fabrication, modeling, and testing of micro-cross-flow heat exchangers, Journal of Microelectromechanical Systems. 11(6) (2002), 726-735.

[24] F. Robinson, J. G. Cevallos, A. Bar-Cohen, and H. Bruck, Modeling and validation of a prototype thermally-enhanced polymer heat exchanger, Proc. ASME 2011 International Mechanical Engineering Congress and Exposition, Denver, CO, 2011, 597-606.

[25] Y. Cormier, P. Dupuis, A. Farjam, A. Corbeil, and B. Jodoin, Additive manufacturing of pyramidal pin fins: Height and fin density effects under forced convection, International Journal of Heat and Mass Transfer. 75 (2014), 235-244.

[26] S. Tsopanos, C. Sutcliffe, and I. Owen, The manufacture of micro cross-flow heat exchangers by selective laser melting, Proceedings of ECI: Fifth International Conference on Enhanced, Compact and Ultra Compact Heat Exchangers, Hoboken, NJ, 2005, 410-417.

[27] M. A. Arie, A. Shooshtari, S. Dessiatoun, and M. Ohadi, Performance characterization of an additively manufactured titanium (Ti64) heat exchanger for an air-water cooling application, Proceedings of the ASME Heat Transfer, Fluids Engineering, \& Nanochannels, Microchannels, and Minichannels Conference HT/FE/ICNMM2016, Washington, DC, 2016.

[28] M. A. Arie, A. H. Shooshtari, V. V. Rao, S. V. Dessiatoun, and M. M. Ohadi, Air side heat transfer enhancement utilizing design optimization and an additive manufacturing technique, (Manuscript submitted for publication)

[29] X. Zhang, M. A. Arie, D. C. Deisenroth, A. H. Shooshtari, S. V. Dessiatoun, and M. M. Ohadi, Impact of additive manufacturing on performance enhancement of heat exchanger: a case study on an air- 
to-air heat exchanger for high temperature applications, IX Minsk International Seminar "Heat Pipes, Peat Pumps, Refrigerators, Power Sources", Minsk, Belarus, 2015, 141-153.

[30] J. G. Cevallos, Thermal and manufacturing design of polymer composite heat exchangers, $\mathrm{PhD}$ thesis, University of Maryland, College Park, MD, 2014.

[31] D. C. Denkenberger, M. J. Brandemuehl, J. M. Pearce, and J. Zhai, Expanded microchannel heat exchanger: design, fabrication, and preliminary experimental test, Proceedings of the Institution of Mechanical Engineers, Part A: Journal of Power and Energy. 226 (2012), 532-544.

[32] D. Denkenberger, M. Parisi, and J.M. Pearce. Towards low-cost microchannel heat exchangers: vehicle heat recovery ventilator prototype, Proceedings of the $10^{\text {th }}$ International Conference on Heat Transfer, Fluid Mechanics and Thermodynamics (HEFAT), Orlando, FL, USA, 2014, 2044-2050 [33] R. Jones, P. Haufe, E. Sells, P. Iravani, V. Olliver, C. Palmer and A. Bowyer, RepRap-the replicating rapid prototype, Robotica. 29(01) (2011), 177-191.

[34] E. Sells, S. Bailard, Z. Smith, A. Bowyer, and V. Olliver, The replicating rapid protoypermaximizing customizability by breeding the means of production. Handbook of Research in Mass Customization and Personalization, Vol 1. World Scientific, New Jersey, 568-580.

[35] A. Bowyer, 3D printing and humanity's first imperfect replicator, 3D Printing and Additive Manufacturing. 1(1) (2014), 4-5.

[36] J.M. Pearce, Open-Source Lab: How to Build Your Own Hardware and Reduce Research Costs, Elsevier, New York, 2013.

[37] B. Wijnen, G.C. Anzalone, A.S. Haselhuhn, P.G. Sanders, and J.M. Pearce, Free and open-source control software for 3-D motion and processing, Journal of Open Research Software. 4(1) (2016), DOI: http://dx.doi.org/10.5334/jors.78

[38] T. L. Bergman, A. S. Lavine, F. P. Incropera, and D. P. Dewitt, Fundamentals of Heat and Mass Transfer, John Wiley \& Sons, 2011.

[39] G. F. Nellis, and S. A. Klein, Heat Transfer, Cambridge University Press, 2009.

[40] B. N. Taylor, and C. E. Kuyatt, C. E., Guidelines for evaluating and expressing the uncertainty of NIST measurement results. NIST Technical Note 1297, 1994.

[41] W. M. Kays, and A. L. London, Compact Heat Exchangers $3^{\text {rd }}$ ed., Krieger, Florida, 1984. 